\title{
Do consumidor de mercadorias ao leitor de jornal: peculiaridades da indústria cultural nas páginas do semanário Flan (1953-1954)
}

Jefferson José Queler*

\section{RESUMO}

Este texto analisa algumas estratégias do jornal semanal Flan para se estabelecer como veículo de repercussão nacional. Ele era parte do grupo Última Hora, fundado e dirigido por Samuel Wainer, e promoveu o governo Vargas durante os anos de 1953 e 1954. O periódico pode ser considerado um dos introdutores da indústria cultural no Brasil. Muitos estudiosos apontaram como esta última esvaziou crescentemente as discussóes públicas, ao implantar a lógica da produção de mercadorias na cultura. Contudo, em seus primeiros passos no país, a indústria cultural, como se nota nas páginas de Flan, parece ter favorecido a formação de leitores de jornais e de mensagens politizadas.

Palavras-chave: indústria cultural; imprensa; Flan; consumo; política.

\begin{abstract}
This paper analyses some strategies of the weekly newspaper Flan to achieve national repercussion. It was part of the Última Hora Group, founded and directed by Samuel Wainer, and promoted Vargas government during 1953 and 1954. The newspaper might be considered as a pioneer of the cultural industry in Brazil. Many scholars have pointed out how such phenomenon increasingly emptied the public debate, by introducing the logic of merchandise production in culture. However, in its first steps in the country, the cultural industry seems to have favored the formation of readers, of newspapers as well as of political messages.
\end{abstract}

Keywords: industrial culture; press; Flan; consumerism; politics.

Artigo recebido em 14 de fevereiro de 2013 e aceito em 8 de maio de 2013.

* Doutor em história pela Universidade de Campinas, professor adjunto do Departamento de História da Universidade Federal de Ouro Preto. Mariana, MG, Brasil. E-mail: jeffqueler@hotmail.com. 
O jornal Flan teve vida relativamente breve. Circulou entre abril de 1953 e setembro de 1954 . Defensor do governo de Getúlio Vargas (1951-1954), saiu de cena pouco depois do suicídio deste último. Recheado de entretenimento e assuntos diversos, foi planejado para atrair leitores em várias partes do país. Porém, não conseguiu consolidar-se entre os grandes semanários nacionais. A análise de suas estratégias para firmar-se no mercado e no cenário político lança luzes sobre as especificidades do processo de instalação da indústria cultural no Brasil. Muitos estudiosos vislumbraram um crescente e linear esvaziamento das discussóes públicas, concomitantemente a uma maior penetração da lógica da produção de mercadorias na confecção de notícias. Entretanto, no caso de Flan é possível observar como o fetiche dos produtos foi instrumentalizado numa série de concursos e promoçôes visando à formação de novos leitores: pessoas capazes de tomar contato com mensagens politizadas do hebdomadário. ${ }^{1}$

\section{O leitor é quem manda: os limites do planejamento na confecção do jornal}

Flan surgiu na primeira metade da década de 1950. Era parte do grupo Última Hora, capitaneado pelo jornalista Samuel Wainer. Anos antes, este último fora crítico do Estado Novo nas páginas da revista Diretrizes. Em 1950, porém, sua relação com Vargas mudou. Trabalhando para os Diários Associados, ele conseguiu entrevistar o então ex-presidente em sua fazenda em São Borja. E a reportagem resultante abriu espaço para a candidatura do político naquele ano. Depois de vencer o pleito, Vargas percebera-se com pouco espaço na imprensa para divulgar os atos de seu governo. Convidou entáo Wainer para fundar um jornal que lhe desse respaldo. Nascia a Última Hora na cidade do Rio de Janeiro, mais tarde estendido para vários estados da federação. Subsidiado por empréstimos oficiais, como muitos outros, o jornal foi ferozmente combatido pela imprensa antigetulista e investigado por uma Comissão Parlamentar de Inquérito (CPI). ${ }^{2}$

Estruturado como empresa, o jornal Última Hora pode ser considerado um dos veículos introdutores da indústria cultural no Brasil: um periódico moldado em larga medida sob a lógica da produção de mercadorias. ${ }^{3}$ Em sua estrutura interna, técnicas de marketing e planejamento foram adotadas para lançá-lo no mercado. Em suas páginas, episódios violentos e entretenimento (esportes, concursos) foram veiculados como forma de atrair leitores. E inovaçóes gráficas, seja na diagramação ou na cobertura fotográfica, buscaram tornar suas mensagens mais chamativas para um público de trabalhadores. No entanto, um viés político foi mantido, notadamente, a defesa do getulismo. Em linhas gerais, advogava a intensificação da industrialização no país por meio de açôes planejadas; o monopólio estatal do petróleo; a manutenção e a ampliação da legislação trabalhista. ${ }^{4}$

Tal processo de racionalização atingia diversos complexos midiáticos no Brasil da década de 1950: imprensa escrita, rádio e a nascente televisão. Segundo Renato Ortiz, a improvisação e a intuição cediam lugar a um maior planejamento na produção de notícias e produtos culturais. Pesquisas de opinião e marketing passaram a ser cada vez mais mobilizados pelas indústrias da comunicação. A figura do manager assumiu lugar de destaque, substituindo, em muitos casos, a do "capitáo da indústria"; ou seja, especialistas em administraçáo tomaram o lugar de muitos empresários pautados por uma lógica familiar ou intuitiva. ${ }^{5}$ No caso específico dos jornais, houve um amplo processo de reforma observado

\footnotetext{
${ }^{1}$ Pesquisa financiada pelo CNPq. Agradeço as sugestôes do parecerista anônimo.

${ }^{2}$ GOLDENSTEIN, Gisela Taschner. Do jornalismo politico à indústria cultural. Sáo Paulo: Summus, 1987. p. 33-55.

${ }^{3}$ A principal matriz teórica de Gisela T. Goldenstein é o seguinte trabalho conjunto de Theodor W. Adorno e Max Horkheimer: A Indústria Cultural: o esclarecimento como mistificação das massas. In: ADORNO, Theodor W.; HORKHEIMER, Max. Dialética do esclarecimento. Rio de Janeiro: Jorge Zahar Editor, 1985. p. 113-157.

${ }^{4}$ GOLDENSTEIN, Gisela T. Do jornalismo politico à indústria cultural, op. cit. p. 33-55.

${ }^{5}$ ORTIZ, Renato. A moderna tradição brasileira: cultura brasileira e indústria cultural. São Paulo: Brasiliense, 2006. p. 134.
} 


\section{Jefferson José Queler}

notadamente no Rio de Janeiro. Além da Última Hora, passam por essas mudanças o Jornal do Brasil, o Diário Carioca e a Tribuna da Imprensa. Foram modificados os critérios de investimento, a veiculação dos classificados, as formas de distribuição e as promoçóes. Nomes de destaque nessa empreitada, afora o de Samuel Wainer, foram Luís Paulistano, Amílcar de Castro, Pompeu de Souza e Alberto Dines. Segundo Ana Paula Goulart Ribeiro, em crítica acertada ao trabalho de Gisela Goldenstein, não havia contradição entre a lógica da empresa jornalística e a lógica da política - ao menos naquele momento, poderíamos acrescentar. ${ }^{6}$ Nas páginas a seguir, gostaria de aprofundar esse viés e indicar como, naquelas circunstâncias, a diretriz mercadológica de um jornal foi mobilizada para politizar amplos segmentos da sociedade.

Flan apareceu como tentativa de reforçar a mensagem getulista e os rendimentos do grupo Última Hora. Nele, escreveram personalidades célebres como Dorival Caymmi, Joel Silveira, Nelson Rodrigues, Orígenes Lessa, dom João de Orleans e Bragança e Otto Lara Rezende. Nas memórias de Samuel Wainer, há indicações sobre o projeto do periódico. Ele conta que tinha a intenção de criar um jornal dominical, "semelhante em alguns aspectos a uma revista, que fosse a síntese das versôes carioca e paulista da Última Hora". ' Conforme as próprias páginas de Flan, os modelos eram os hebdomadários franceses Ici Paris e France Dimanche. Seus principais concorrentes no Brasil eram a prestigiada revista O Cruzeiro, parte dos Diários Associados e sob comando de Assis Chateaubriand; e a revista Manchete, dando então seus primeiros passos sob a liderança de Adolfo Bloch. Tomando o exemplo de ambas, procurou constituir-se como veículo de circulação nacional. Segundo Samuel Wainer, Flan logo alcançou altas tiragens, despertando a ira da concorrência:

A pressão contra Flan começou a tornar-se violentíssima. [Carlos] Lacerda sustentava que eu investira naquele empreendimento milhóes de cruzeiros - e milhóes financiados pelo governo. Era uma evidente mentira; o semanário fora lançado sem que eu pedisse um único tostão ao governo. Chateaubriand chantageava meus anunciantes, decidido a retirar-me a sustentaçấo financeira. Depois de quatro, cinco meses, Flan começou a perder qualidade. (...) Um dia, melancolicamente, morreu, sem que seu desaparecimento provocasse qualquer comoção. ${ }^{8}$

Evidentemente, a explicação de Wainer para o fechamento de Flan, ao apontar a disputa por mercado entre empresários da imprensa, deve ser levada em conta. Porém, o fator político não deve ser desconsiderado, pois Lacerda e Chateaubriand eram adversários ferrenhos do getulismo, apregoado nas páginas do jornal. Não se deve perder de vista, enfim, razóes internas ao próprio grupo Última Hora, o qual não conseguiu repetir o sucesso de seu primeiro periódico.

\footnotetext{
${ }^{6}$ RIBEIRO, Ana Paula Goulart. Jornalismo, literatura e política. Estudos Históricos, Rio de Janeiro, v. 1, n. 31, p. 156, 2003.

${ }^{7}$ WAINER, Samuel. Minha razão de viver: memórias de um repórter. Rio de Janeiro: Record, 1988. p. 166.

${ }^{8}$ Ibid., p. 168.
} 
Figura 1

Política: em defesa do petróleo nacional

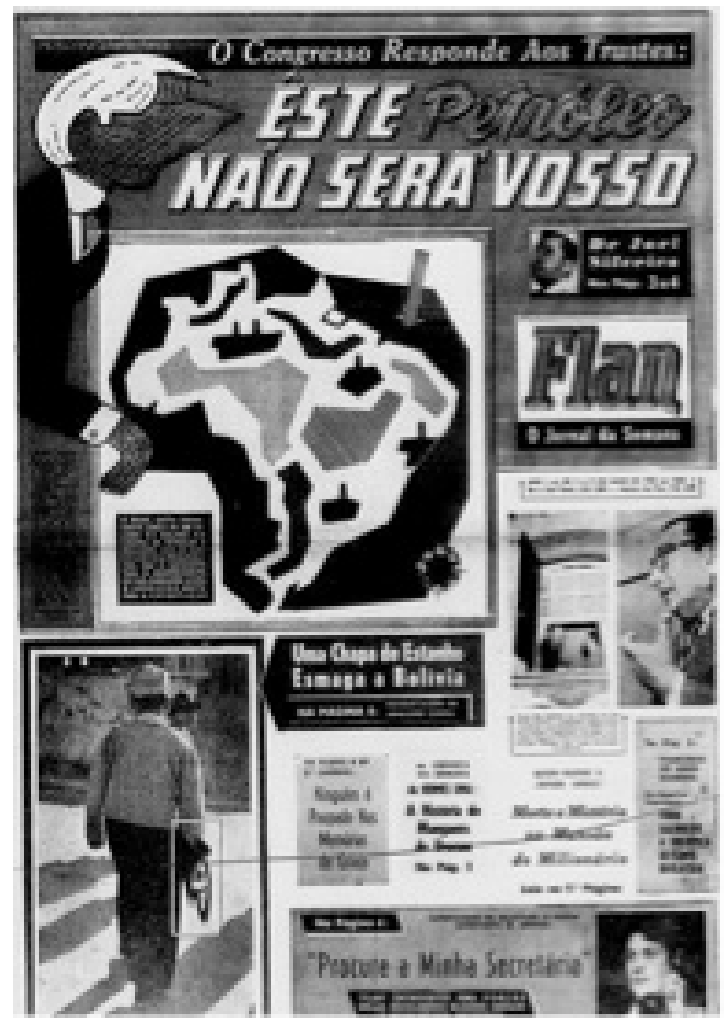

Fonte: Flan (3-9 maio 1953, capa).

Segundo a própria explicação da equipe editorial, fornecida em razão da dúvida de um leitor, o nome Flan referia-se a termo muito utilizado em jornais. Tratava-se de uma matriz ou de um molde de página a ser impresso, tirado em papelão especial. ${ }^{9}$ Com o lançamento anunciado em volantes de propaganda, o veículo buscava racionalizar a produção de seu conteúdo, gabando-se disso, inclusive: "FLAN, como jornal consciencioso, só surgiu nas bancas depois de acurados estudos, depois de minuciosamente planejado pelos melhores técnicos" ${ }^{10}$ Segundo informaçôes do próprio jornal, sua primeira tiragem alcançou 160 mil exemplares, distribuídos por todo o território nacional. Declarando-se sem anunciantes, abria a possibilidade de veiculação de propaganda. ${ }^{11}$ Seu intuito explícito: atingir públicos os mais diversos possíveis; o primeiro caderno, com "inquietaçóes políticas" no Brasil e no mundo, era destinado "ao senhor"; o segundo, com informaçóes sobre rádio, moda, cinema e teatro, "passaremos à sua senhora"; o terceiro, com crônicas a respeito do Rio de Janeiro e do mundo dos esportes, "confiaremos a seu filho". Mesmo assim, o jornal afirmava que essas seçóes não eram estanques ou talhadas apenas para determinado grupo social, podendo ser lidas pelos mais diversos públicos. ${ }^{12}$

As pesquisas de opinião não foram o único recurso empregado para estruturar o jornal. Um importante indicador para avaliar a aceitação de suas mensagens residia nas cartas enviadas pelos leitores à redação, conforme indica trecho da primeira edição: "É evidente que um jornal não vive exclusivamente do esforço de seus diretores e redatores. Vive também das sugestóes e críticas indispensáveis dos que o leem. Flan, mais do que qualquer outra publicação, não fechará os ouvidos às queixas e aos palpites

\footnotetext{
${ }^{9}$ Flan, 14-20 jun. 1953. O leitor escreve a Flan, p. 2.

${ }^{10}$ Flan, 3-9 maio 1953. Flan escreve ao leitor, p. 2.

${ }^{11}$ Flan, 19-25 abr. 1953. Flan escreve ao leitor, p. 2.

${ }^{12}$ Flan, 12-18 abr. 1953. Flan escreve ao leitor, p. 2.
} 
de seu público". ${ }^{13}$ Houve até mesmo a institucionalização de um prêmio em dinheiro para estimular o recebimento de conselhos. Ao que parece, a forma do periódico foi acerbamente criticada nos primeiros momentos de sua existência:

O primeiro número (segundo nos disseram francamente vários leitores) se ressentia de certa densidade, que se era qualidade, por um lado, era também, por outro, um obstáculo à sua leitura. Houve quem dissesse que FLAN estava tão denso que não se sabia como e por onde entrar... Pois bem; o segundo número, trazendo embora igual volume de matéria interessante e legível, caminhou bastante no sentido da agilidade e da leveza. Tornou-se mais acessível. ${ }^{14}$

O formato do jornal parece ter sido considerado objeto de negociação. A carta de Pedro Perez, de Neves (RJ), pode ter sido publicada como sinal de que o periódico acatava algumas das exigências de seu público: "Leitor assíduo de FLAN, gostei de ver a nova paginação e o novo feitio de FLAN. Agora as coisas ali estão mais agrupadas e mais lógicas" ${ }^{15}$ Por mais que houvesse planejamento, o periódico buscou consolidar-se no mercado tateando os interesses de seu público, bem como o modo de veiculá-los. Conforme indica o sociólogo inglês John Thompson, receptores de mensagens midiáticas têm a possibilidade de intervir no conteúdo das mesmas; podem escrever cartas para o responsável pelo programa ou pela publicação, telefonar para companhias de televisão e expressar seus pontos de vista, ou simplesmente recusar-se a comprar produtos propagandeados na mídia. Esses exemplos mostram que, por mais que o processo de comunicação seja assimétrico, ele não é inteiramente monológico ou de via única. ${ }^{16}$ Em outras palavras, a indústria cultural que se formava no Brasil, na década de 1950, precisou levar em conta muitos dos interesses de seus consumidores. Por mais que os conteúdos e as formas das mensagens midiáticas tenham sido planejados, foi preciso negociá-los constantemente com grupos sociais, ao menos no caso de Flan. ${ }^{17}$

Numa de suas ediçóes, a equipe de Flan relatou o recebimento de muitas cartas. Porém, demonstrou insatisfação com o predomínio de elogios e aprovaçôes. ${ }^{18} \mathrm{Em}$ contrapartida, conclamou o leitor a apontar "senão uma falha, ao menos alguma deficiência que tenha observado em nossas páginas": ${ }^{19}$ um patamar para os planejadores reformularem as mensagens do periódico segundo as demandas de seus consumidores. Muitas vezes, o diálogo com as solicitaçôes dos leitores foi explicitado como forma de exibir o atendimento de alguma delas, mecanismo para promover maior identificação entre ambos. Por exemplo, as diretrizes de Oswaldo Ferreira, de São Paulo (SP), ganhador de um dos prêmios em dinheiro, foram apresentadas e receberam o compromisso de atendimento. Ele teria ouvido reclamaçôes de que Flan era um jornal caro, tendo-se em conta que outras publicaçôes de menor volume custavam bem menos. A equipe do periódico, por sua vez, defendeu-se: "não vendemos volume de papel, mas qualidade"; ao mesmo tempo que ressaltou o acolhimento da demanda: "quanto ao peso material, ninguém perde por esperar. FLAN irá também aumentando o seu. Já hoje aparece com um

\footnotetext{
${ }^{13}$ Ibid.

${ }^{14}$ Flan, 26 abr.-2 maio 1953. Flan escreve ao leitor, p. 2.

${ }^{15}$ Flan, 27 dez. 1953-2 jan. 1954. O leitor escreve a Flan, p. 46.

16 THOMPSON, John B. The media and modernity. California: Stanford University, 1995. p. 25.

${ }^{17}$ Sobre o papel criativo dos consumidores de mensagens, ver: CERTEAU, Michel de. A invenção do cotidiano. 1. Artes de fazer. Petrópolis: Vozes, 1994. p. 37-47.

${ }^{18} \mathrm{Em}$ estudo que lida com cartas enviadas à equipe encarregada da produção do Almanaque Abril, Mateus Henrique de Faria Pereira identificou não apenas casos de consumidores críticos do conteúdo da publicação, como também numerosos casos de missivistas que aceitaram os conteúdos dela. PEREIRA, Mateus Henrique de Faria. A máquina da memória: o tempo presente entre a história e o jornalismo. Bauru: Edusc, 2009. p. 108-124.

${ }^{19}$ Flan, n. 5, 11-16 maio 1953. O leitor escreve a Flan, p. 02.
} 
quarto caderno". Segundo as sugestôes de Oswaldo Ferreira, a inclusão de um índice para cada um dos cadernos facilitaria a leitura, indicação que lhe rendeu elogios da equipe de Flan. ${ }^{20}$ É possível imaginar que a publicação desta carta, bem como os apontamentos do atendimento de suas demandas representassem caso exemplar de pressóes semelhantes veiculadas por outros leitores.

Em sua vigésima edição, Flan declarou atender a pedidos de leitores das mais distantes localidades do país. Afirmou ter mudado seu formato para tornar o jornal mais cômodo e mais fácil de ser manuseado, conforme as solicitaçôes recebidas: "Alguns achavam FLAN difícil de ser lido. Outros opinavam ser demasiadamente grande o seu tamanho. Houve quem sugerisse, até, esse novo molde, que começamos a apresentar a partir de hoje”. O novo arranjo gráfico, segundo anunciava, também auxiliaria o leitor a encontrar a matéria de sua predileção. ${ }^{21}$ Uma espécie de pacto com o público consumidor era proposto.

Flan era apresentado como exemplo de inovação e sintonia com as mais modernas técnicas de impressão. Náo por acaso, relatou o envio à Europa de Antônio Nássara, um dos membros de sua equipe, para tomar contato com métodos tidos como inovadores na produção de jornais. Em seguida, segundo a notícia, tais procedimentos seriam aplicados nas oficinas de Flan. ${ }^{22} \mathrm{Um}$ possível artifício para convencer o leitor da qualidade técnica da publicação, assim como para atribuir-lhe um apelo cosmopolita. O jornal pretendia firma-se como órgão de circulaçáo nacional. Tudo indica ser esse o motivo da saudação da solicitação de Pietro Grassa, da cidade do Rio de Janeiro. Ele pediu para que Flan retratasse uma cidade do interior a cada domingo, passo para ampliar o processo de identificaçáo com o periódico ao longo do país: "Outros leitores já nos sugeriram o mesmo - e estamos em que é possível realizar o desejo dos que, residindo no interior, desejam ver suas cidades mais conhecidas pelo Brasil". ${ }^{23}$ É o caso de Teófilo Mesquita, de Ponte Nova (MG), que solicita ao jornal o não esquecimento dos problemas do interior. Em sua sugestão, Flan devia enviar um repórter munido de máquina fotográfica aos rincóes do país, de modo a ver o que se "passa, de bom e de ruim, por esse Brasil afora". Na resposta da redação, a intenção de incorporar esse conselho ficava patente: "FLAN está sempre presente em todos os acontecimentos de importância no Rio e nos Estados, uma vez que a preocupação número um da nossa publicação é a de fazer um jornal cem por cento nacional, e não apenas local". ${ }^{24}$

As cartas de leitores podiam servir como parâmetro para estabelecer limites durante a confecção das mensagens. É o que aponta correspondência de Vicente de Paulo Melillo, em nome da Confederação das Famílias Cristãs. O jornal não explicitou o teor das reivindicaçôes do missivista, manifestando apenas a disposição em adotar a "orientação sadia" preconizada pela Comissão de Moral e Costumes daquela instituição. Já a demanda de Maxime Charles Barrault explicitava os temas que lhe despertavam contrariedade. Manifestou-se contra a publicação de fotografias "horríveis, impressionantes, como de restos esquartejados", conseguindo o compromisso do jornal em não veicular material com esse tipo de conteúdo. ${ }^{25}$

Por outro lado, a correspondência atuava como termômetro para identificar temas que despertassem amplo interesse. A página de charges do periódico, interrompida durante algum tempo, parece ter sido reivindicada por muitos leitores. Como resposta, a equipe editorial declarou a intenção de estudar seu restabelecimento em razão do agrado despertado junto ao público, "que é, afinal, quem manda". ${ }^{26}$ Luiz Coutinho de Souza, de São Gonçalo (RJ), exibe uma série de sugestôes: uma seção com o título

${ }^{20}$ Flan, n. 5, 11-16 maio 1953. O leitor escreve a Flan, p. 2.

${ }^{21}$ Flan, n. 20, 23-29 ago. 1953. O leitor escreve a Flan, p. 4.

${ }^{22}$ Flan, 7-13 jun. 1953. p. 2.

${ }^{23}$ Flan, 14-20 jun. 1953. O leitor escreve a Flan, p. 2.

${ }^{24}$ Flan, 21-27 mar. 1954. O leitor escreve a Flan, p. 7.

${ }^{25}$ Flan, 24-30 maio 1953. O leitor escreve a Flan, p. 2.

${ }^{26}$ Ibid., p. 2. 
"Conheça o Brasil"; outra destinada à divulgação de assuntos relacionados à higiene (profilaxia de doenças, conselhos médicos); e uma terceira com perguntas e respostas sobre todos os temas. A equipe do jornal indica ter anotado os direcionamentos, cuja adoção seria estudada. ${ }^{27}$ E Maria Ercília, de Paranaguá (PR), mostrou-se incomodada com a recorrência de retratos de mulheres com pouca roupa nas páginas de Flan; em sua opiniáo, estratégia deste último para agradar o público masculino. Por outro lado, propôs: "Sente-se (...) que falta uma mulher na orientação desse grande semanário, porque senão, não digo sempre, mas de vez em quando poderiam publicar algumas fotos de homens bonitos e fortes para agradar também a sensibilidade estética das leitoras". ${ }^{28}$ Mesmo que muitas dessas solicitaçóes não tenham sido atendidas, o compromisso do jornal com elas soava ao menos como uma disposição em ouvi-las e incorporá-las.

O que pretendia a equipe do jornal através desse diálogo com seus leitores? Umberto Eco relatou situação interessante que ilumina os exemplos anteriores. Ele mencionou ocasião em que Chester Gould, autor do personagem Dick Tracy, fez morrer o gângster Flattop. Em seguida, surpreendentemente, comunidades citadinas inteiras decretaram luto e milhares de telegramas criticaram o autor, pedindo-lhe satisfações pelo ocorrido. Segundo Eco: "O histerismo provém da frustração de uma operação empatizante, uma vez que passa a faltar o suporte físico de projeções necessárias". ${ }^{29}$ Eis um dos grandes objetivos da equipe de Flan, ampliar sua empatia com o público leitor; operaçáo sempre incompleta, dada a diversidade de interesses sociais, mas que procurou se tornar a mais ampla possível.

Mesmo em situaçóes em que não atendia seu público, o jornal procurou deixar claro que dialogava com ele. M. Martins, de Piracicaba (SP), chegou a sugerir a dedicação de espaço no periódico a comentários sobre música. Obteve a seguinte resposta: "Anotamos sua sugestão. Concordamos com o leitor: a música é, realmente, um tema fascinante. O problema reside, apenas, na nossa atual crise de espaço”. ${ }^{30}$ De fato, tendo chegado a atingir mais de sessenta páginas, Flan agonizava com 24 páginas na ocasião. Mostra de que todo o planejamento que recebeu, bem como todos os reajustes que a ele se impuseram, não foram suficientes para manter o periódico em circulação, o que sugere limites à indústria cultural à época.

\section{Estratégias para a formação de leitores de jornal}

Flan não se restringiu apenas a considerar algumas das reivindicações e pressões de seus leitores. Buscou também atrair novos consumidores, seja entre clientes de outros periódicos, seja entre pessoas não habituadas a ler notícias. Com isso, procurou consolidar-se no mercado editorial traçando estratégias para firmar-se no longo prazo. Como vimos, o jornal pretendia granjear um maior número de leitores propalando a qualidade de suas mensagens. Para tanto, uma série de estratégias foram mobilizadas. $\mathrm{O}$ mercado de bens duráveis em expansão à época constituiu-se em chamariz para atrair novos consumidores.

Um dos primeiros desafios do jornal foi apresentar-se para um público que até então o desconhecia. Para tanto, readaptando experiência utilizada durante a criação do jornal Última Hora, criou um Departamento de Promoçóes e Concursos e promoveu uma série de sorteios intitulada "Prêmios para toda a família". Liquidificadores, enceradeiras, ferros de passar, máquinas fotográficas figuravam entre as premiaçóes. Para concorrer, era preciso comprar o jornal durante ao menos quatro semanas

\footnotetext{
${ }^{27}$ Flan, 17-23 maio 1953. O leitor escreve a Flan, p. 2.

${ }^{28}$ Flan, 18-24 out. 1953. O leitor escreve a Flan, p. 59.

${ }^{29}$ ECO, Umberto. Apocalípticos e integrados. São Paulo: Perspectiva, 1990. p. 246.

${ }^{30}$ Flan, 20-26 jun. 1954. Terceiro caderno, O leitor escreve a Flan, p. 6.
} 


\section{Jefferson José Queler}

seguidas. Em cada uma delas, uma das letras do nome Flan surgia, devendo o pretendente recortá-la e guardá-la. Após juntar todas as peças e formar o conjunto, ele podia trocá-lo por um cupom numerado em postos autorizados, com o qual passava a concorrer a uma variedade de produtos. Os sorteios eram realizados, inicialmente, pela Rádio Clube do Brasil. Os números eram tirados no programa Ciranda dos Bairros, transmitido para o Rio de Janeiro e outras cidades aos domingos, com audiência estimada em 2 mil pessoas. ${ }^{31}$ Poucos meses depois, o certame passou a ocorrer na Rádio Mayrink Veiga, no programa Silveira Lima. Tudo indica que a equipe do jornal pretendia atrair potenciais leitores entre pessoas alfabetizadas e acostumadas a ouvir rádio. A estratégia consistia em estimular a compra do periódico durante um mês, como forma de apresentá-lo e divulgá-lo. Os atrativos eram tanto o fetiche das mercadorias quanto o entretenimento oferecido pelos eventos promocionais.

\section{Figura 2}

Promessa de entretenimento como meio para criar consumidores habituais

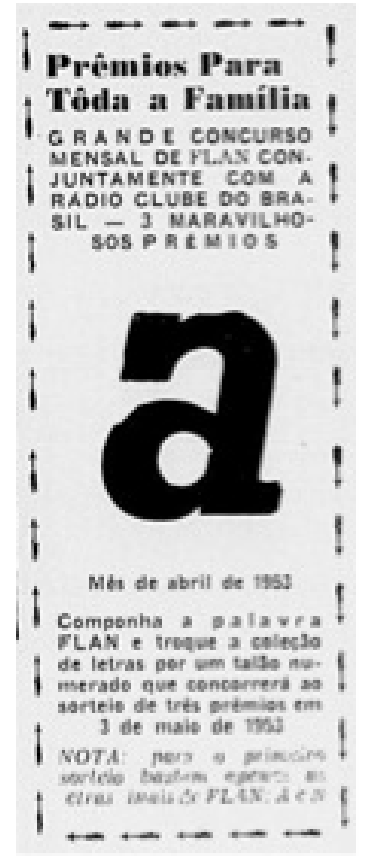

Fonte: Flan (19-25 abr. 1953, p. 23).

No Brasil da década de 1950, é preciso lembrar, estava em curso a construção de uma economia moderna, marcada pela adoção de padróes de produção e consumo próprios aos países desenvolvidos: eletrodomésticos, remédios, produtos de beleza, automóveis passaram a ser cada vez mais produzidos e utilizados no país. A possibilidade de consumir tais objetos, muitas vezes, assumia a condição de indicador da classe social do indivíduo. E as camadas mais baixas da população apressaram-se em mimetizar os padróes de consumo e o estilo de vida dos grupos mais abastados. ${ }^{32}$ Neste mercado, em que se acirrava a concorrência entre grandes empresas monopolistas, a publicidade surgia como peça fundamental para o lançamento e a consolidação de marcas. Ela abria caminho para a diminuição do tempo entre a produção e o consumo das mercadorias. Segundo Maria Arminda do Nascimento

\footnotetext{
${ }^{31}$ Flan, 3-9 maio 1953. Terceiro caderno, Prêmios para toda a família, p. 10.

${ }^{32}$ NOVAIS, Fernando; MELLO, João Manuel Cardoso. Capitalismo tardio e sociabilidade moderna. In: SCHWARCZ, Lilia Moritz (Org.). História da vida privada no Brasil. São Paulo: Companhia das Letras, 1998. p. 562 e 604.
} 


\section{Jefferson José Queler}

Arruda, as campanhas publicitárias do período tendiam a associar os produtos a um princípio de utilidade, contribuindo para fetichizar as mercadorias e criar a falsa ideia de que o capitalismo é o reino do valor de uso. ${ }^{33}$ Em sua análise:

Num contexto em que a produção dos setores de ponta assenta-se na diversificação das mercadorias e cujo mercado é numericamente estreito, a publicidade torna-se uma peça fundamental, inerente ao planejamento das grandes empresas. Evidentemente, o seu grau na reprodução é o mesmo, quer seja nos países centrais ou periféricos. Não obstante, é preciso muito mais esforço para convencer poucos a consumir mais do que induzir muitos a comprar bastante. ${ }^{34}$

Poderíamos questionar a suposta força avassaladora da publicidade na criação de necessidades. Entretanto, as reflexóes da autora levam-nos a pensar que os esforços publicitários de Flan podem ser mais bem compreendidos se pensarmos num mercado de revistas e jornais altamente competitivo e concentrado em torno de algumas empresas. ${ }^{35}$ A equipe do periódico parecia disputar uma fatia desse segmento, ao criar seu próprio Departamento de Promoçóes e Concursos. Mais do que isso, buscou construir parte de seu próprio mercado, servindo-se de entretenimento cujos prêmios remetiam a mercadorias elas próprias já envoltas em publicidade, o que em parte explica os desejos projetados sobre elas.

\section{Figura 3}

O fetiche das mercadorias como atrativo

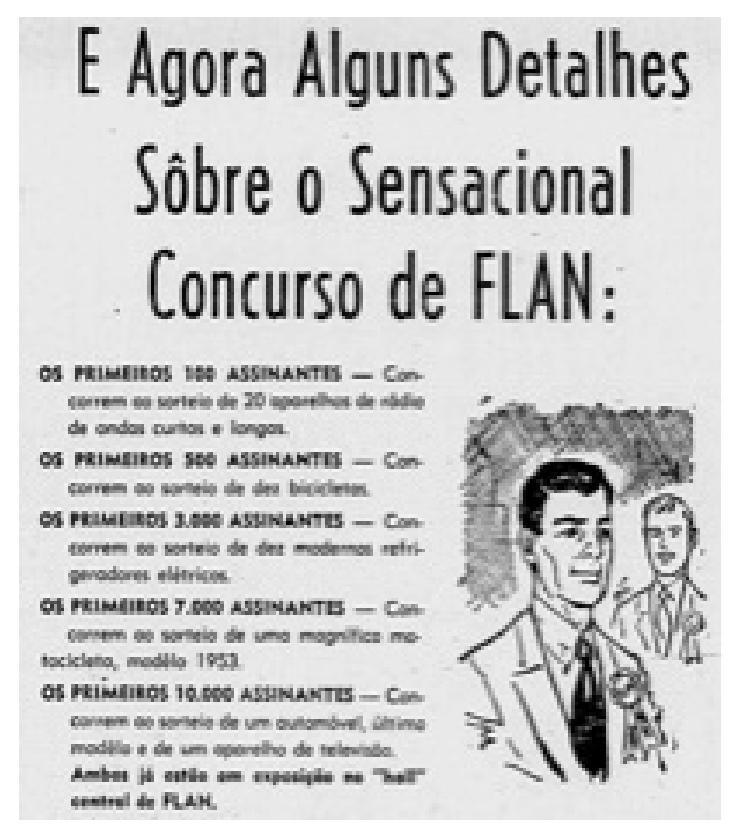

Fonte: Flan (3-9 maio 1953, p. 10).

\footnotetext{
${ }^{33}$ ARRUDA, Maria Arminda do Nascimento. A embalagem do sistema: a publicidade no capitalismo brasileiro. Bauru: Edusc, 2004. p. 76.

${ }^{34}$ Ibid., p. 141-142.

${ }^{35}$ Segundo Nelson Werneck Sodré, na década de 1950, "A concentração da imprensa seguia seu curso inexorável; tornava-se cada vez mais difícil lançar jornal novo; o número dos que desapareciam era crescente. Finda a Guerra Mundial, abria-se amplo horizonte à liberdade de pensamento; cada vez mais se verificava, na prática, que tal liberdade era meramente retórica: só grandes capitais poderiam montar grandes empresas, como os jornais". SODRÉ, Nelson Werneck. História da Imprensa no Brasil. Rio de Janeiro: Mauad, 1999. p. 395.
} 


\section{Jefferson José Queler}

Os potenciais consumidores de Flan eram estimulados a adquiri-lo com prêmios distribuídos em sorteios. Os primeiros cem assinantes concorreriam a vinte rádios; os primeiros quinhentos, a dez bicicletas; os primeiros 3 mil, a dez geladeiras; os primeiros 7 mil, a uma motocicleta; os primeiros 10 mil, a uma televisão e a um automóvel; ao que tudo indica, objetos bastante desejados à época, na medida em que sua virtual posse era empregada como atrativo para potenciais assinantes. Veja-se o exemplo de oferta de geladeiras como prêmios, em que o jornal afirmou estarem tais aparelhos ausentes do mercado ou com os preços majorados: "Ganhar, por conseguinte, uma, simplesmente pelo fato de ser assinante de FLAN, é um presente dos céus. E qual a dona de casa não aspira possuir a sua geladeira?”. ${ }^{36}$ Outro caso pode ser vislumbrado na premiaçáo concedida por meio de uma bolsa de estudos para a obtenção de uma habilitação na Escola Loide para Motoristas. ${ }^{37}$ Curioso é que encontrei, nas páginas de Flan, propaganda desta instituição com a seguinte conclamação: "APRENDA A DIRIGIR. Saber não ocupa lugar! O carro virá depois.... ${ }^{38} \mathrm{O}$ que sugere a ânsia pelo consumo dessas mercadorias à época, não à toa mobilizada pela equipe do jornal para atrair eventuais consumidores. Dessa forma, o fetiche de certas mercadorias e o entretenimento foram mobilizados pelo jornal para a constituição de um público de leitores.

\section{Entretenimento e decodificação de notícias}

Diversão e promessas de admissão num grupo social eram formas de atrair leitores e estimulá-los a identificar fatos. Novos consumidores do jornal eram seduzidos com a proposta de serem integrados a uma comunidade. Na quarta edição surgiu a proposta de formação do "Clube de assinantes FLAN". Todos os sócios teriam direito a um distintivo, para poder se reconhecer na rua; entre eles, uma vez atingida a marca de 10 mil assinantes, deputados seriam eleitos para uma Convenção Organizadora do Clube; suas atividades, estimular programas artísticos regionais, intercâmbios culturais, caravanas da amizade, concursos de confraternização, conferências. Eis a explicação da equipe do jornal para essa iniciativa:

Acreditamos que dois assinantes de FLAN tenham motivos para ser bons amigos. Acreditamos que num ocasional encontro de rua eles possam identificar-se e trocar ao menos um olhar de simpatia. Acreditamos enfim, que esse é um meio a mais de que dispóe FLAN para estimular a aproximação e a cordialidade da família brasileira, possibilitando a confraternização direta entre o assinante do Piauí e o do Rio, entre o cearense e o mineiro, entre o paulista e o mato-grossense. ${ }^{39}$

$\mathrm{Na}$ edição seguinte, apareceu o significado de ser membro do clube: "o leitor que incorpora-se, de certa forma, à nossa organização. Não é um leitor comum, mas um amigo em contato permanente conosco e que, por isso mesmo, tem direitos especiais, inclusive o de INFLUIR na organizaçáo geral de FLAN". ${ }^{40} \mathrm{Na}$ nona edição, surgiu a promessa de que todos os sócios seriam convocados para uma assembleia geral. Tenha ela ocorrido ou não, a ideia do clube parece não ter vingado, uma vez que, em todas as ediçóes posteriores, não houve menção alguma à continuidade do projeto. De qualquer modo, a estratégia da equipe do jornal residia não apenas em promover novos canais de interlocução com o

\footnotetext{
${ }^{36}$ Flan, $13-19$ set. 1953 . p. 61.

37 Ibid.

${ }^{38}$ Flan, 20-26 set. 1953. p. 52.

${ }^{39}$ Flan, 3-9 maio 1953. Que é o clube dos assinantes de FLAN?, p. 10

${ }^{40}$ Flan, 11-16 maio 1953. O que é o clube dos assinantes de FLAN?, p. 10.
} 
público leitor, de modo a canalizar as demandas dele; ela também pretendia oferecer laços de sociabilidade e a sensação de pertencimento a um grupo. ${ }^{41}$

Após cativar pessoas a comprar o jornal, o desafio de Flan consistia em torná-las seus leitores habituais. Ao que parece, estava em jogo também a tentativa de criar o hábito de leitura da imprensa escrita. Para tanto, a equipe do periódico institucionalizou um concurso de fotografias. De início, publicava três imagens por semana, solicitando aos leitores que compusessem legendas "jornalísticas" para elas. ${ }^{42}$ Como prêmios, outra série de mercadorias. Logo no quinto número de Flan apareceu a indicação de que muitos leitores não se adaptaram ao formato do concurso. Por meio de cartas dirigidas ao Departamento de Promoçóes e Concursos, reclamavam da dificuldade na composiçáo das legendas, e por isso solicitavam maior facilidade. E o jornal parece ter cedido a algumas dessas pressóes, modificando seu "interessante passatempo": "Basta, então, apenas identificar as fotografias — as três — para concorrer aos três prêmios de 500 cruzeiros. Não é mais preciso fazer as legendas e, afinal, nem todos têm vocação para jornalista...”. ${ }^{43}$ Em edição posterior, o número de fotografias caiu para uma, tornando o certame ainda mais fácil e com o atrativo de que "daremos um prêmio de valor e utilidade: um rádio, um liquidificador etc." ${ }^{44}$ Segundo os propósitos do periódico, a intenção era não "só de dar prêmios, mas também de apresentar um entretenimento agradável". ${ }^{5}$

\section{Figura 4}

Da imagem à palavra escrita: estratégia para a formação de leitores

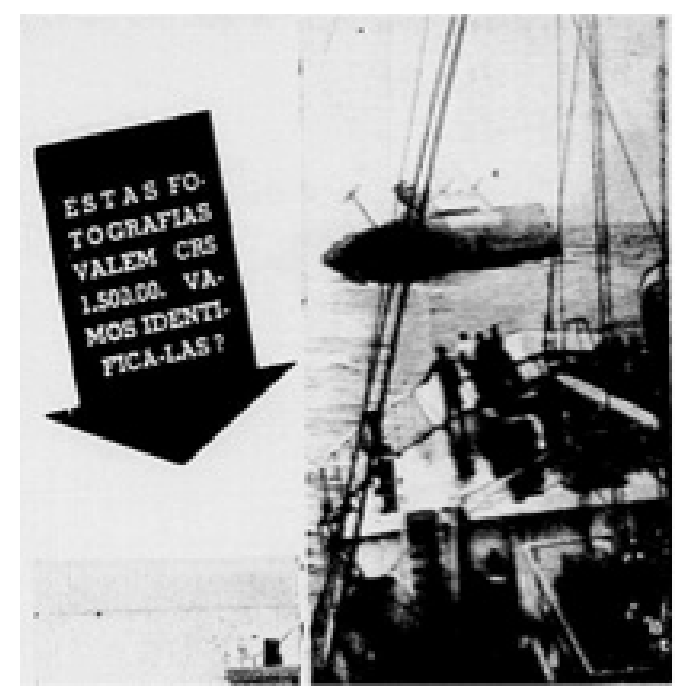

Fonte: Flan (19-25 abril 1953, p. 23).

\footnotetext{
${ }^{41}$ Em sua crítica conservadora à sociedade de massas, Gabriel Tarde percebeu o potencial dos jornais em erigir e manter laços sociais. Em sua observação, homens que não se veem nem se tocam podem constituir liames por meio da imprensa: "estão sentados cada um em sua casa, lendo o mesmo jornal e dispersos num vasto território. Qual é, pois, o vínculo que existe entre eles? Esse vínculo é, juntamente com a simultaneidade de sua convicção ou de sua paixão, a consciência que cada um deles possui de que essa ideia ou essa vontade é partilhada no mesmo momento por um grande número de outros homens". TARDE, Gabriel. A opinião e as massas. São Paulo: Martins Fontes, 2005. p. 6 e 7. Benedict Anderson, por sua vez, vislumbrou na imprensa um dos grandes agentes na conformação de "comunidades imaginadas" em torno de distintos ideais de nação. ANDERSON, Benedict. Comunidades imaginadas. São Paulo: Companhia das Letras, 2008. p. 54-55.

42 Flan, 3-9 maio 1953. Terceiro caderno, Prêmios para toda a família, p. 10.

${ }^{43}$ Flan, 11-16 maio 1953. Terceiro caderno, p. 11.

${ }^{44}$ Flan, 23-29 ago. 1953. p. 61.

${ }^{45}$ Flan, 19-25 jul. 1953. p. 7.
} 
Se levarmos em conta a noção de jogo delineada por Johan Huizinga, há um detalhe que dificulta sua aplicaçáo em tais casos. $\mathrm{O}$ autor o considerou uma atividade livre, conscientemente tomada como não séria e alheia à vida habitual. Seu potencial é o de absorver o jogador de maneira intensa e total, e promover a formação de grupos sociais com tendências a cercar-se de segredo e a demarcar sua distinção em relação ao restante do mundo. Ademais: "É uma atividade desligada de todo e qualquer interesse material, com a qual náo se pode obter qualquer lucro, praticada dentro de limites espaciais e temporais próprios, segundo uma certa ordem e certas regras". " Os concursos de Flan apresentavam regras, eram realizados em determinados espaços, pretendiam extrapolar a vida ordinária. Contudo, eles ofereciam premiaçóes materiais, objetos e mercadorias de vários tipos. De qualquer forma, a equipe do jornal procurou atrair leitores com atividades que se aproximavam do jogo, fugindo um pouco da seriedade normalmente atribuída às notícias.

O artifício do concurso de fotografias, por meio de uma atividade apresentada como lúdica, buscava formar o hábito de leitura entre os consumidores do jornal. Afinal, era preciso ler o periódico para saber a quais acontecimentos remetiam as fotos. Tarefa complicada, pois muitos leitores confundiam as cenas expostas com acontecimentos mais próximos de seu cotidiano. Numa de suas ediçôes, por exemplo, a equipe de Flan estampou o retrato do navio norte-americano Flying Enterprise adernado. O fato havia sido amplamente noticiado nos dias precedentes. Chamou a atenção especialmente pela atitude de seu comandante, o capitáo Carlsson, último a abandonar o barco. No momento de identificar o retrato, porém: "Centenas e centenas de leitores confundiram a cena com o afundamento do 'Magdalena', na Guanabara". ${ }^{47}$ Em outra ocasião, foi estampada uma foto do atleta Geraldo de Oliveira. Este, porém, foi largamente confundido com Ademar Ferreira da Silva, campeão em Helsinki. Apesar de reconhecer a semelhança entre eles, o jornal advertiu: "Associando-se essa parecença com a sequência de fotos que lembrava o famoso salto-tríplice, o resultado foi que ninguém teve o cuidado de examinar detidamente as fotografias, julgando logo que aquela fosse a barbada". ${ }^{48}$

Por meio de diálogos com as demandas de seus leitores, Flan parece ter atingido uma forma de entretenimento passível de formar novos leitores. "Basta usar a memória!", proclamava a coluna do teste fotográfico. E relata a melhor recepção do novo formato do concurso. Com a sua simplificação, o número de cartas teria aumentado bastante, o que levou a equipe do jornal a deduzir: "Pelo visto, os leitores preferem usar a memória" que "recorrer à inspiração". Algumas pessoas, por outro lado, prendiam-se ainda ao primeiro formato do certame: "Temos notado que alguns leitores ainda fazem legendas enquanto outros se limitam a dar informaçóes um tanto vagas, sobre o assunto das fotografias. Queremos, por isso, esclarecer que uns e outros incorrem em equívocos" ${ }^{49} \mathrm{O}$ noticiário internacional parecia ser mais dificilmente apreendido. Após expor a foto do ex-rei Faruk com a princesa Narriman, retrato que o jornal pressupunha ser de fácil identificação, a surpresa de que: "não obstante terem andado no noticiário da imprensa mundial ainda recentemente, não estão de todo conhecidos da grande massa de leitores dos jornais". ${ }^{50}$

Cobrava-se a identificação precisa dos fatos representados nos retratos. Em sua quadragésima edição, por exemplo, o jornal publicou fotografia do técnico Zezé Moreira junto de Rivadavia Correia Meyer, presidente da CBD. No concurso, muitas pessoas confundiram o último com outras personalidades. Porém, a grande maioria dos leitores identificou as duas figuras. No resultado da disputa, apenas um leitor teria fornecido a resposta correta. Apontou que a foto fora tirada no dia da indicação de Zezé

\footnotetext{
${ }^{46}$ HUIZINGA, Johan. Homo ludens. São Paulo: Perspectiva, 2010. p. 18.

${ }^{47}$ Flan, 11-16 maio 1953. Terceiro caderno, p. 11.

${ }^{48}$ Flan, 17-23 maio 1953. Terceiro caderno, p. 11.

${ }^{49}$ Flan, 24-30 maio 1953. Segundo caderno, p. 11.

${ }^{50}$ Flan, 13-19 set. 1953. p. 29.
} 
para técnico da seleção brasileira durante a Copa do Mundo. A descrição do detalhe é indicada como o segredo do acerto. Afinal, "Fotos dos dois desportistas juntos há muitas. Mas que identifique aquele fato só mesmo a que apresentamos". E o sr. Wilson teria se destacado, "não esquecendo de mencionar o fato que a estampa recordava". ${ }^{1}$

A princípio, os concorrentes podiam tomar conhecimento dos fatos através de quaisquer jornais. É o que apontam os comentários do periódico ao apresentar o teste na ediçáo 63: "O leitor deve lembrar-se de algo que toda a imprensa, nos últimos dias, muito comentou, com fotografias, e depois dar a sua solução". ${ }^{52}$ Porém, muitas vezes era explicitado o projeto de formar leitores dos periódicos do grupo Última Hora. Certa vez, ao publicar foto da refinaria de Mataripe, muitos identificaram nela outras instalaçôes. Volta Redonda, oleoduto São Paulo-Santos, refinaria de Abadan (Irã) foram algumas das respostas. Como solução para o problema de se definir com precisão fatos da atualidade: "O leitor, que lê muito jornal e especialmente ÚLTIMA HORA e FLAN, certo estará em dia com todos os grandes acontecimentos, como aquele que está, numa de suas fases, focalizado na foto em questão.". ${ }^{3}$

Por vezes, a fotografia solicitada era publicada com exclusividade nesses dois periódicos, de modo que os concorrentes, caso quisessem participar da competição, deviam obrigatoriamente lê-los. É o caso do concurso apresentado na edição 45 de Flan: "A foto é dos Índios da Tribo Tchuchruamãe, do alto Xingu e foi publicada nas ediçôes de ÚLTIMA HORA do Rio e de São Paulo e também em FLAN. A chance que demos aos leitores, por conseguinte, foi enorme". ${ }^{4}$ Sobre esta foto, outra edição do jornal informou terem muitos leitores confundido a referida tribo com índios caiapós, botocudos, xavantes, ou até mesmo ter vislumbrado as comemoraçóes do quarto centenário paulista no retrato. Outros, porém, "muito vivos, sem dúvida, anexaram a foto primitivamente publicada, na reportagem de (FLAN no 43 ) que inspirou o teste" ${ }^{55}$ Neste caso, a equipe do jornal foi flexível; valorizou o consumidor de jornal que identificou a imagem por meio de uma cópia dela publicada em edição anterior. Porém, os exemplos sugerem que havia um projeto de transformar leitores de imagens em leitores de textos. É o que deixa bem explícita a seguinte apresentação do teste fotográfico: "Quem está em dia com a leitura dos jornais diários não terá dificuldade em matar o problema e, assim, habilitar-se ao brinde". ${ }^{56}$ Ao que tudo indica, o jornal pretendia criar competências e hábitos entre seus consumidores para que eles pudessem interpretar as mais diversas formas de mensagens nele veiculadas.

De forma subliminar, é possível identificar nesses concursos o propósito não apenas de formar leitores. Estava em jogo também a possibilidade de eles adquirirem experiências durante o processo de interpretação de notícias. John Thompson indica que, no mundo contemporâneo, o self é flexível e aberto a experimentar acontecimentos, fatos e valores provindos de outros espaços e tempos, os quais são veiculados pelas mais diversas mídias. ${ }^{57}$ Essa possibilidade efetivamente existe. Porém, tendo em conta as estratégias mercadológicas e políticas de Flan, deveríamos chamar a atenção para a necessidade de um processo relativamente longo de aprendizado: para que experiências pudessem ser adquiridas por meio de jornais, era premente uma grande familiaridade com a identificação e a interpretação de fatos.

\footnotetext{
${ }^{51}$ Flan, 24-30 jan. 1954. p. 39.

${ }^{52}$ Flan, 27 jun.-3 jul. 1954. Terceiro caderno, p. 5.

${ }^{53}$ Flan, 17-23 jan. 1954. p. 35.

${ }^{54}$ Flan, 14-20 fev. 1954. p. 43.

${ }^{55}$ Flan, 21-27 fev. 1954. p. 37.

${ }^{56}$ Flan, 11-17 abr. 1954. Caderno 3, p. 5.

57 THOMPSON, John B. The media and modernity, op. cit. p. 117.
} 


\section{Jefferson José Queler}

\section{Consideraçóes finais}

A indústria cultural consolidada no Brasil ao longo dos anos da ditadura militar inclinou-se claramente a despolitizar os conteúdos dos mais diversos veículos midiáticos. ${ }^{58}$ Entretanto, seria um equívoco considerar essa tendência como a única forma assumida por ela no país ao longo de sua trajetória. Em seus primeiros passos, não apenas não havia contradição entre a lógica de produção de mercadorias e orientaçôes políticas, como também a primeira foi utilizada para reforçar a última. O mercado de bens de consumo duráveis, em plena expansão na década de 1950, foi mobilizado para a ampliação do número de leitores de um jornal envolvido nos debates públicos, como é o caso de Flan, defensor do getulismo. $\mathrm{O}$ fetiche de diversos produtos assumiu a condição de chamariz para a conversão de consumidores de mercadorias em decodificadores de notícias. Por meio de uma série de concursos, o jornal buscou atrair um conjunto de assinantes capaz de tornar a empresa rentável e de difundir suas posiçóes políticas. Geladeiras, ferros de passar, batedeiras, rádios, motocicletas e carros passaram a ser oferecidos como prêmios àqueles que tomassem contato com o recém-criado semanário. Em jogo, encontrava-se também a intenção de transformar seus leitores ocasionais em seus leitores habituais. Daí a necessidade de adquirir o periódico por semanas seguidas para se poder participar dos certames. Enfim, os novos adeptos da publicação deveriam estar aptos a interpretar as mensagens nela veiculadas; eis por que fotos eram exibidas num dos concursos, com o intuito de estimular os leitores a relacionarem-nas aos acontecimentos que elas representavam. Portanto, pessoas acostumadas a atuar como consumidoras no mercado podiam ser integradas às discussões públicas.

Os jornais, normalmente, apresentam-se pautados por uma "missão de imprensa", ou seja, órgãos supostamente imparciais. Na prática, porém, interesses diversos atuam na conformação de suas mensagens. Seja por depender de publicidade, ou por temer afastar seus assinantes e leitores com determinados tipos de notícia, a maioria dos periódicos tende a se calar diante de algumas questóes e posicionar-se em relação a pautas tidas como menos controvertidas. De qualquer forma, no caso específico de Flan, é preciso destacar que as demandas de muitos de seus leitores foram adotadas por sua equipe, a qual precisou ceder em alguns de seus planos iniciais. A racionalização da produção de notícias, fundada em pesquisas de opinião e planejamento, incorporou diversas críticas e demandas dos consumidores do jornal. Dessa forma, pode-se notar não apenas a especificidade dos caminhos percorridos pela indústria cultural no Brasil, mas também os limites que lhe foram impostos no âmbito do regime democrático vigente na década de 1950: contrapesos praticamente silenciados em boa parte dos chamados anos de chumbo.

${ }^{58}$ ORTIZ, Renato. A moderna tradição brasileira, op. cit. p. 124. 